\title{
AN INFLUENCE OF THE WINKLER ELASTIC FOUNDATION OF A GEOMETRICALLY NONLINEAR COLUMN LOADED BY FORCE DIRECTED TOWARDS THE POSITIVE POLE ON A TYPE OF SYSTEM
}

\author{
Anna Jurczyńska, Janusz Szmidla \\ Institute of Mechanics and Machine Design Foundation, Czestochowa University of Technology \\ Częstochowa, Poland \\ a.jurczynska@imipkm.czest.pl,szmidla@imipkm.pcz.czest.pl
}

\begin{abstract}
Depending on the mutual relation between external load, tendon's length parameter resulting from the direction of loading force and the free vibration frequency parameter, the slope of characteristic curves of a considered column subjected to force directed towards the positive pole can take the negative, zero and positive value. The purpose of this paper is to determine the criterion that allows for classification of an analysed structure to divergent or divergent pseudo-fluttering type of system. On the basis of obtained formulas, the ranges of parameters describing the Winkler elastic foundation for which the considered system may be classified as one of the abovementioned types were determined.
\end{abstract}

Keywords: slender systems, Winkler elastic foundation, stability, free vibrations

\section{Introduction}

Due to the course of curves on the plane external load - free vibrations frequency, the slender systems can be classified into four types: divergent, fluttering, hybrid and divergent pseudo-fluttering (see [1-3]). In article [4], on the basis of criterion of loss of stability by divergence, it has been stated that the slope of characteristic curves of conservative columns (systems that lose stability with buckling) is always a negative value. In works $[1,2,5,6]$ it has been proven that structures under specific load (combining properties of the follower force or generalised load with force directed towards the pole) can be considered as a divergent pseudo-fluttering type. The stability and free vibrations of structure under a generalised load with force directed toward the pole were analysed in publications [1,6]. Results of numerical calculation concerning free vibrations and stability of columns loaded by the follower force directed towards the pole were presented in works $[2,6]$. In both cases the angles of the tangents to obtained characteristic curves can take positive, zero and negative values. It was found that the main factors determining the change in the type of system are parameters describing the geometry of 
the loading head, stiffness of spring supporting structure and the stiffness of elastic foundation. The influence of the stiffness of elastic foundation on the local instability was discussed in $[7,8]$.

\section{The physical model of the system}

A geometrically nonlinear column locally resting on a one-parameter Winkler elastic foundation is analysed. The considered system is loaded by force directed towards the positive pole. The following variants of the structure are examined:

NW - geometrically nonlinear column (compare [9]), whose internal rod was supported at a certain section $l_{d}$ on Winkler elastic base with stiffness $K$ (see Fig. 1). The location of the elastic foundation is determined by dimension $l_{c}$. In order to model local supporting, the internal rod was divided into three parts with flexural stiffness $(E J)_{2},(E J)_{3}$ and $(E J)_{4}$, compressive stiffness $(E A)_{2},(E A)_{3}$ and $(E A)_{4}$ and mass per unit length $(\rho A)_{2},(\rho A)_{3}$ and $(\rho A)_{4}$ respectively, where:

$$
\begin{aligned}
& (E J)_{2}=(E J)_{3}=(E J)_{4}, \\
& (E A)_{2}=(E A)_{3}=(E A)_{4}, \\
& (\rho A)_{2}=(\rho A)_{3}=(\rho A)_{4} .
\end{aligned}
$$

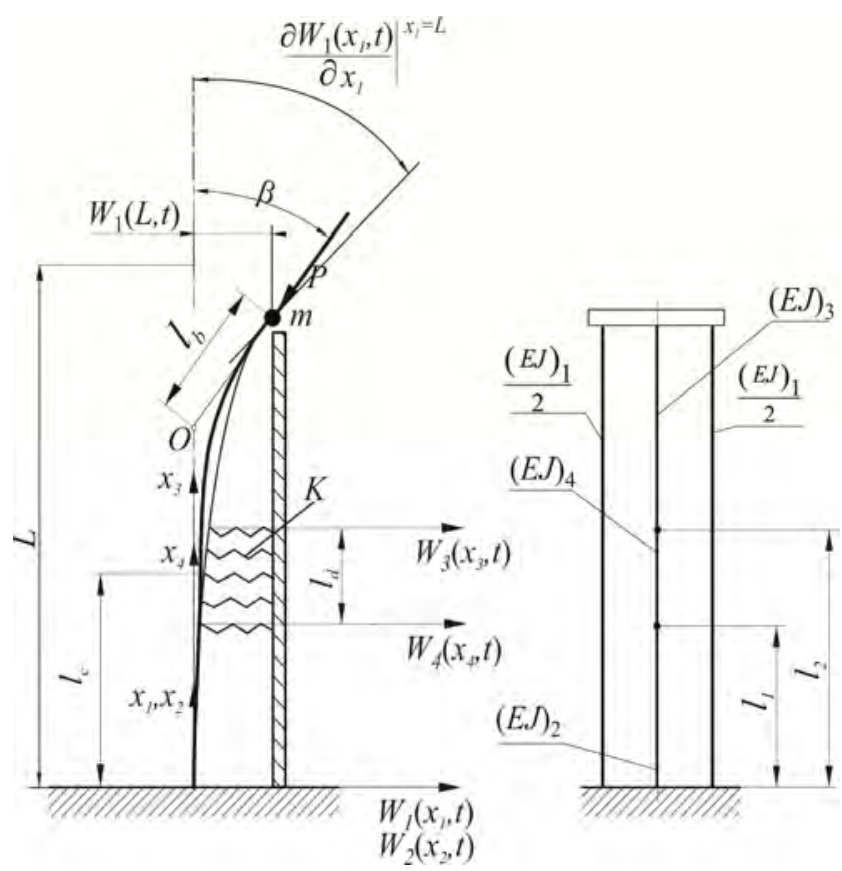

Fig. 1. The physical model of a geometrically nonlinear column (compare [9]) locally resting on Winkler foundation NW 
Flexural stiffness of system was described by the coefficient of the flexural stiffness distribution $\mu$ :

$$
\mu=\frac{(E J)_{2}}{(E J)_{1}} .
$$

It is assumed that total flexural stiffness is constant:

$$
(E J)_{1}+(E J)_{2}=\text { const }
$$

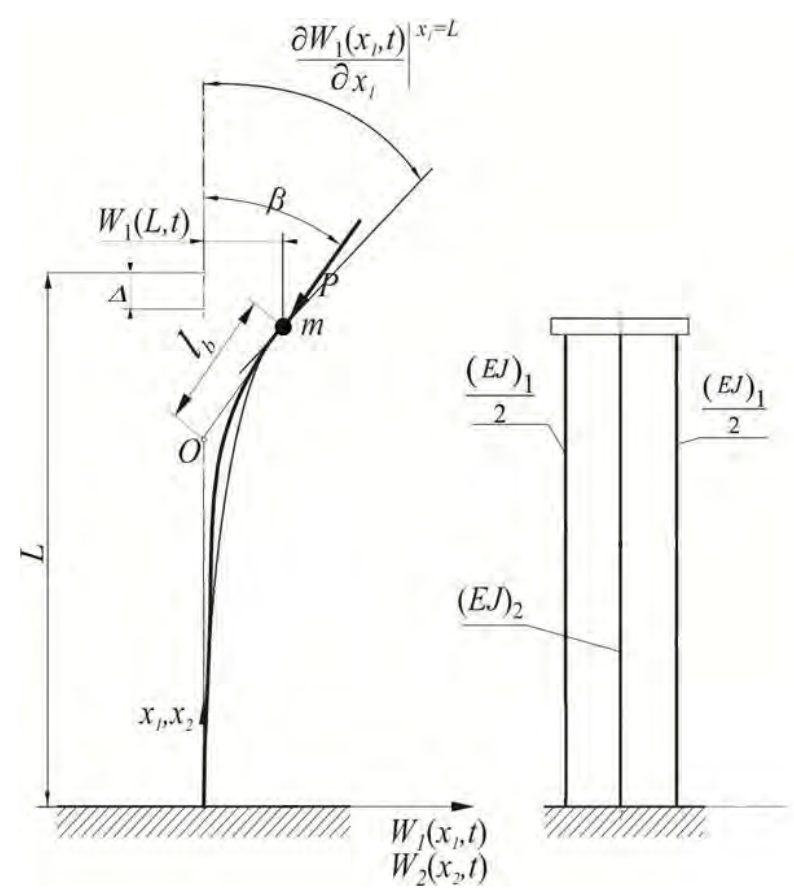

Fig. 2. The physical model of geometrically nonlinear column $\mathbf{N}$

$\mathbf{N}$ - geometrically nonlinear column built of three rods connected with each other by concentrated mass $m$ that ensures the same deflections and angles of deflections at the free end of system (Fig. 2). In order to simplify the calculations, two external rods are considered as one rod with total flexural stiffness $(E J)_{1}$.

\section{Mechanical energy of system, equations of motion and boundary conditions}

Taking into consideration the physical model of a geometrically nonlinear column locally resting on Winkler elastic foundation NW, on the basis of the Bernoulli-Euler theory the potential energy $V$ and the kinetic energy $T$ were determined as follows: 


$$
\begin{aligned}
& V=\frac{1}{2}(E J)_{1} \int_{0}^{L}\left(\frac{\partial^{2} W_{1}\left(x_{1}, t\right)}{\partial x_{1}{ }^{2}}\right)^{2} d x_{1}+\frac{1}{2}(E J)_{2} \int_{0}^{l_{1}}\left(\frac{\partial^{2} W_{2}\left(x_{2}, t\right)}{\partial x_{2}{ }^{2}}\right)^{2} d x_{2}+\frac{1}{2}(E J)_{3} \int_{l_{2}}^{L}\left(\frac{\partial^{2} W_{3}\left(x_{3}, t\right)}{\partial x_{3}{ }^{2}}\right)^{2} d x_{3}+ \\
& +\frac{1}{2}(E J)_{4} \int_{l_{1}}^{l_{1}}\left[\frac{\partial^{2} W_{4}\left(x_{4}, t\right)}{\partial x_{4}{ }^{2}}\right)^{2} d x_{4}+\frac{1}{2}(E A)_{1} \int_{0}^{L}\left[\frac{1}{2}\left(\frac{\partial W_{1}\left(x_{1}, t\right)}{\partial x_{1}}\right)^{2}+\frac{\partial U_{1}\left(x_{1}, t\right)}{\partial x_{1}}\right]^{2} d x_{1}+ \\
& +\frac{1}{2}(E A)_{2} \int_{0}^{l_{1}}\left[\frac{1}{2}\left(\frac{\partial W_{2}\left(x_{2}, t\right)}{\partial x_{2}}\right)^{2}+\frac{\partial U_{2}\left(x_{2}, t\right)}{\partial x_{2}}\right]^{2} d x_{2}+\frac{1}{2}(E A)_{3} \int_{l_{2}}^{L}\left[\frac{1}{2}\left(\frac{\partial W_{3}\left(x_{3}, t\right)}{\partial x_{3}}\right)^{2}+\frac{\partial U_{3}\left(x_{3}, t\right)}{\partial x_{3}}\right]^{2} d x_{3}+ \\
& +\frac{1}{2}(E A)_{4} \int_{l_{1}}^{l_{2}}\left[\frac{1}{2}\left(\frac{\partial W_{4}\left(x_{4}, t\right)}{\partial x_{4}}\right)^{2}+\frac{\partial U_{4}\left(x_{4}, t\right)}{\partial x_{4}}\right]^{2} d x_{4}+P \Delta+\frac{1}{2} P W_{1}(L, t) \sin \beta+\frac{1}{2} K \int_{l_{1}}^{l_{2}}\left(W_{4}\left(x_{4}, t\right)\right)^{2} d x_{4},
\end{aligned}
$$

$$
\begin{aligned}
& T=\frac{1}{2}(\rho A)_{1} \int_{0}^{L}\left(\frac{\partial W_{1}\left(x_{1}, t\right)}{\partial t}\right)^{2} d x_{1}+\frac{1}{2}(\rho A)_{2} \int_{0}^{l_{1}}\left(\frac{\partial W_{2}\left(x_{2}, t\right)}{\partial t}\right)^{2} d x_{2}+ \\
& +\frac{1}{2}(\rho A)_{3} \int_{l_{2}}^{L}\left(\frac{\partial W_{3}\left(x_{3}, t\right)}{\partial t}\right)^{2} d x_{3}+\frac{1}{2}(\rho A)_{4} \int_{l_{1}}^{l_{2}}\left(\frac{\partial W_{4}\left(x_{4}, t\right)}{\partial t}\right)^{2} d x_{4}+\frac{1}{2} m\left(\left.\frac{\partial W_{1}\left(x_{1}, t\right)}{\partial t}\right|_{x_{1}=L}\right)^{2},
\end{aligned}
$$

where:

$\Delta=U_{1}(L, t)$,

$U_{1}\left(x_{1}, t\right), U_{2}\left(x_{2}, t\right), U_{3}\left(x_{3}, t\right), U_{4}\left(x_{4}, t\right)$ - longitudinal displacements.

The issue of free vibrations of the column was formulated on the basis of Hamilton's principle [10] (Eq. (8)) using properties of variational calculus:

$$
\delta \int_{t_{1}}^{t_{2}}(T-V) d t=0 .
$$

Known a priori geometrical boundary and continuity conditions can be written as:

$$
\begin{array}{ll}
W_{1}(0, t)=W_{2}(0, t)=0, & W_{1}(L, t)=W_{3}\left(L-l_{2}, t\right), \\
\left.\frac{\partial W_{1}\left(x_{1}, t\right)}{\partial x_{1}}\right|_{x_{1}=0}=\left.\frac{\partial W_{2}\left(x_{2}, t\right)}{\partial x_{2}}\right|_{x_{2}=0}=0, & \left.\frac{\partial W_{1}\left(x_{1}, t\right)}{\partial x_{1}}\right|_{x_{1}=L}=\left.\frac{\partial W_{3}\left(x_{3}, t\right)}{\partial x_{3}}\right|_{x_{3}=L-l_{2}}, \\
W_{2}\left(l_{1}, t\right)=W_{4}(0, t), & W_{4}\left(l_{2}-l_{1}, t\right)=W_{3}(0, t), \\
\left.\frac{\partial W_{2}\left(x_{2}, t\right)}{\partial x_{2}}\right|_{x_{2}=l_{1}}=\left.\frac{\partial W_{4}\left(x_{4}, t\right)}{\partial x_{4}}\right|_{x_{4}=0}, & \left.\frac{\partial W_{4}\left(x_{4}, t\right)}{\partial x_{4}}\right|_{x_{4}=l_{2}-l_{1}}=\left.\frac{\partial W_{3}\left(x_{3}, t\right)}{\partial x_{3}}\right|_{x_{3}=0},
\end{array}
$$


where:

$$
l_{1}=l_{c}-\frac{l_{d}}{2}, \quad l_{2}=l_{c}+\frac{l_{d}}{2} .
$$

The distribution of an internal load in each rod of the column was described as follows:

$$
S_{i}=P \frac{(E A)_{i}}{(E A)_{1}+(E A)_{2}}, \quad i=1,2,3,4
$$

where $S_{2}=S_{3}=S_{4}$.

Taking into account variation of mechanical energy (6), (7) in equation (8), using expressions (9)-(18), the following relations were obtained:

- differential equations of motion:

$$
\begin{aligned}
& (E J)_{j} \frac{\partial^{4} W_{j}\left(x_{j}, t\right)}{\partial x_{j}^{4}}+S_{j} \frac{\partial^{2} W_{j}\left(x_{j}, t\right)}{\partial x_{j}^{2}}+(\rho A)_{j} \frac{\partial^{2} W_{j}\left(x_{j}, t\right)}{\partial t^{2}}=0, \quad j=1,2,3 \\
& (E J)_{4} \frac{\partial^{4} W_{4}\left(x_{4}, t\right)}{\partial x_{4}^{4}}+S_{4} \frac{\partial^{2} W_{4}\left(x_{4}, t\right)}{\partial x_{4}^{2}}+(\rho A)_{4} \frac{\partial^{2} W_{4}\left(x_{4}, t\right)}{\partial t^{2}}+K W_{4}\left(x_{4}, t\right)=0
\end{aligned}
$$

- natural boundary conditions:

$$
\begin{gathered}
\left.\frac{\partial^{2} W_{1}\left(x_{1}, t\right)}{\partial x_{1}^{2}}\right|_{x_{1}=L}+\left.\mu \frac{\partial^{2} W_{3}\left(x_{3}, t\right)}{\partial x_{3}^{2}}\right|_{x_{3}=L-l_{2}}=0 \\
\left.(E J)_{1} \frac{\partial^{3} W_{1}\left(x_{1}, t\right)}{\partial x_{1}{ }^{3}}\right|_{x_{1}=L}+\left.(E J)_{3} \frac{\partial^{3} W_{3}\left(x_{3}, t\right)}{\partial x_{3}{ }^{3}}\right|_{x_{3}=L-l_{2}}+P\left[\left.\frac{\partial W_{1}\left(x_{1}, t\right)}{\partial x_{1}}\right|_{x_{1}=L}-\frac{W_{1}(L, t)}{l_{b}}\right]+ \\
-\left.m \frac{\partial^{2} W_{1}(L, t)}{\partial t^{2}}\right|_{=0}
\end{gathered}
$$

- natural continuity conditions:

$$
\begin{aligned}
& \left.\frac{\partial^{2} W_{2}\left(x_{2}, t\right)}{\partial x_{2}{ }^{2}}\right|_{x_{2}=l_{1}}=\left.\frac{\partial^{2} W_{4}\left(x_{4}, t\right)}{\partial x_{4}{ }^{2}}\right|_{x_{4}=0},\left.\quad \frac{\partial^{2} W_{4}\left(x_{4}, t\right)}{\partial x_{4}{ }^{2}}\right|_{x_{4}=l_{2}-l_{1}}=\left.\frac{\partial^{2} W_{3}\left(x_{3}, t\right)}{\partial x_{3}{ }^{2}}\right|_{x_{3}=0}, \\
& \left.\frac{\partial^{3} W_{2}\left(x_{2}, t\right)}{\partial x_{2}{ }^{3}}\right|_{x_{2}=l_{1}}=\left.\frac{\partial^{3} W_{4}\left(x_{4}, t\right)}{\partial x_{4}{ }^{3}}\right|_{x_{4}=0},\left.\quad \frac{\partial^{3} W_{4}\left(x_{4}, t\right)}{\partial x_{4}{ }^{3}}\right|_{x_{4}=l_{2}-l_{1}}=\left.\frac{\partial^{3} W_{3}\left(x_{3}, t\right)}{\partial x_{3}{ }^{3}}\right|_{x_{3}=0} .
\end{aligned}
$$




\section{Results of numerical calculations}

In order to be able to compare results of numerical calculations the following dimensionless parameters were used:

- dimensionless parameter of external load

$$
\lambda=\frac{P L^{2}}{\sum_{i=1}^{2}(E J)_{i}},
$$

- parameter of free vibration frequency

$$
\Omega=\frac{\sum_{i=1}^{2}(\rho A)_{i} \omega^{2} L^{4}}{\sum_{i=1}^{2}(E J)_{i}},
$$

- length of tendon parameter

$$
l_{b}^{*}=\frac{l_{b}}{L},
$$

- parameters describing the Winkler elastic foundation: stiffness $K^{*}$, length $l_{d}{ }^{*}$, location $l_{c}^{*}$ :

$$
K^{*}=\frac{K L^{4}}{\sum_{i=1}^{2}(E J)_{i}}, \quad l_{d}^{*}=\frac{l_{d}}{L}, \quad l_{c}^{*}=\frac{l_{c}}{L} .
$$

In Figure 3 the courses of characteristic curves (curves on the plane parameter of free vibration frequency - parameter of external load) were presented for $\mathbf{N}$ and NW columns, respectively. The slope of curves corresponding to the first natural frequency may be only negative (a divergent type of system) or negative, zero and positive (a divergent pseudo-fluttering type of system).

In the case of an analysed column loaded by force directed towards the positive pole, belonging to particular type of system, is heavily determined by length of the tendon parameter. Courses of curves on the plane free vibration frequency external load are additionally influenced by taking into consideration an elastic foundation. 
a)

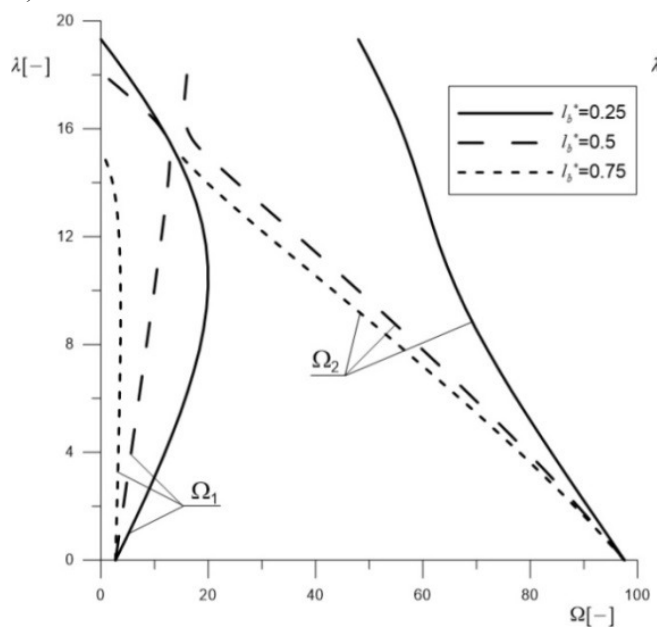

b)

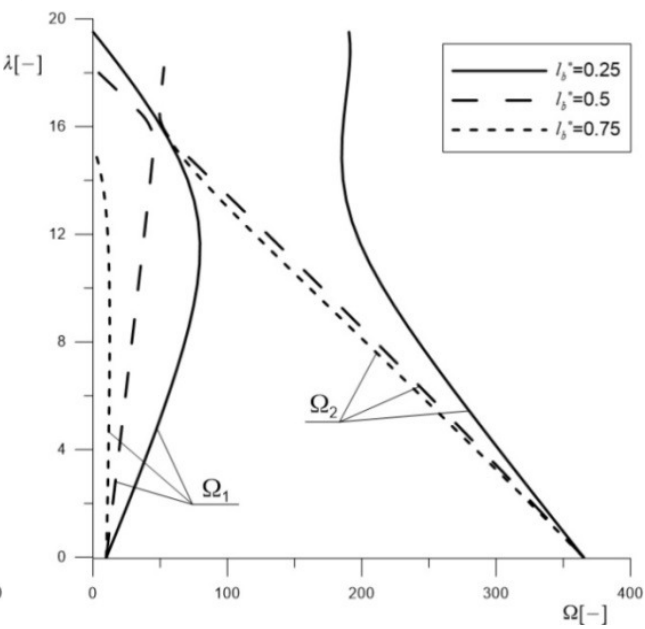

Fig. 3. The first two free vibration frequencies curves for different values of tendon's length parameter $l_{b}{ }^{*}:$ a) column $\mathbf{N}$, b) column $\mathbf{N W}$.

The dimensionless coefficient of the flexural stiffness distribution $\mu=0.3$, parameters describing elastic foundation:

$$
K^{*}=10, l_{c}^{*}=0.5, l_{d}^{*}=0.8
$$

\section{The criterion for determining a type of system}

Analogously to articles $[4,10]$, differential equations of motion (21)-(22) were formulated in the following form:

$$
\begin{gathered}
w_{11}^{I V}\left(\xi_{1}\right)+\lambda_{I} w_{11}^{I I}\left(\xi_{1}\right)-\Omega_{I} w_{11}\left(\xi_{1}\right)=0, \\
\mu w_{21}^{I V}\left(\xi_{2}\right)+\lambda_{I} \beta w_{21}^{I I}\left(\xi_{2}\right)-\varphi \Omega_{I} w_{21}\left(\xi_{2}\right)=0, \\
\mu w_{31}^{I V}\left(\xi_{3}\right)+\lambda_{I} \beta w_{31}^{I I}\left(\xi_{3}\right)-\varphi \Omega_{I} w_{31}\left(\xi_{3}\right)=0, \\
\mu w_{41}^{I V}\left(\xi_{4}\right)+\lambda_{I} \beta w_{41}^{I I}\left(\xi_{4}\right)-\varphi \Omega_{I} w_{41}\left(\xi_{4}\right)+K_{1} \mu w_{41}\left(\xi_{4}\right)=0,
\end{gathered}
$$

where:

$$
\lambda_{I}=\frac{P L^{2}}{(1+\beta)(E J)_{1}}, \quad \Omega_{I}=\frac{(\rho A)_{1} \omega_{0}^{2} L^{4}}{(E J)_{1}}, \quad \beta=\frac{(E A)_{2}}{(E A)_{1}}, \quad \varphi=\frac{(\rho A)_{2}}{(\rho A)_{1}} .
$$


The following integral - differential formula is analysed:

$$
\begin{aligned}
& F\left[w_{11}\left(\xi_{1}\right), w_{21}\left(\xi_{2}\right), w_{31}\left(\xi_{3}\right), w_{41}\left(\xi_{4}\right)\right]=\int_{0}^{1} w_{11}\left(\xi_{1}\right)\left[w_{11}^{I V}\left(\xi_{1}\right)+\lambda_{I} w_{11}^{I I}\left(\xi_{1}\right)-\Omega_{10} w_{11}\left(\xi_{1}\right)\right] d \xi_{1}+ \\
& +\int_{0}^{1} w_{21}\left(\xi_{2}\right)\left[\mu w_{21}^{I V}\left(\xi_{2}\right)+\lambda_{I} \beta w_{21}^{I I}\left(\xi_{2}\right)-\varphi \Omega_{10} w_{21}\left(\xi_{2}\right)\right] d \xi_{2}+ \\
& +\int_{0}^{1} w_{31}\left(\xi_{3}\right)\left[\mu w_{31}^{I V}\left(\xi_{3}\right)+\lambda_{I} \beta w_{31}^{I I}\left(\xi_{3}\right)-\varphi \Omega_{10} w_{31}\left(\xi_{3}\right)\right] d \xi_{3}+ \\
& +\int_{0}^{1} w_{41}\left(\xi_{4}\right)\left[\mu w_{41}^{I V}\left(\xi_{4}\right)+\lambda_{I} \beta w_{41}^{I I}\left(\xi_{4}\right)-\varphi \Omega_{10} w_{41}\left(\xi_{4}\right)+K_{1} \mu w_{41}\left(\xi_{4}\right)\right] d \xi_{2} .
\end{aligned}
$$

Integral (43) is a function of the variables $\lambda_{\mathrm{I}}$ and $\Omega_{\mathrm{I}}$. It is assumed that the stiffness of elastic foundation $K_{1}$ is constant and does not depend on load parameter $\lambda_{\mathrm{I}}$. By differentiating both sides of equation (43) with respect to $\lambda_{\mathrm{I}}$, grouping expressions and multiplying both sides by $d \lambda_{\mathrm{I}}$ it was obtained:

$$
\begin{aligned}
& d F\left[w_{11}\left(\xi_{1}\right), w_{21}\left(\xi_{2}\right), w_{31}\left(\xi_{3}\right), w_{41}\left(\xi_{4}\right)\right]=d \lambda_{I} \int_{0}^{1} w_{11}^{I I}\left(\xi_{1}\right) w_{11}\left(\xi_{1}\right) d \xi_{1}-d \Omega_{I} \int_{0}^{1} w_{11}^{2}\left(\xi_{1}\right) d \xi_{1}+ \\
& +\int_{0}^{1}\left[w_{11}^{I V}\left(\xi_{1}\right)+\lambda_{I} w_{11}^{I I}\left(\xi_{1}\right)-\Omega_{I} w_{11}\left(\xi_{1}\right)\right] d w_{11}\left(\xi_{1}\right) d \xi_{1}+ \\
& +\int_{0}^{1}\left[d w_{11}^{I V}\left(\xi_{1}\right)+\lambda_{I} d w_{11}^{I I}\left(\xi_{1}\right)-\Omega_{I} d w_{11}\left(\xi_{1}\right)\right] w_{11}\left(\xi_{1}\right) d \xi_{1}+ \\
& +d \lambda_{I} \beta \int_{0}^{1} w_{21}^{I I}\left(\xi_{2}\right) w_{21}\left(\xi_{2}\right) d \xi_{2}-\varphi d \Omega_{I} \int_{0}^{1} w_{21}^{2}\left(\xi_{2}\right) d \xi_{2}+ \\
& +\int_{0}^{1}\left[\mu w_{21}^{I V}\left(\xi_{2}\right)+\lambda_{I} \beta w_{21}^{I I}\left(\xi_{2}\right)-\varphi \Omega_{I} w_{21}\left(\xi_{2}\right)\right] d w_{21}\left(\xi_{2}\right) d \xi_{2}+ \\
& +\frac{\int_{0}^{1}\left[\mu d w_{21}^{I V}\left(\xi_{2}\right)+\lambda_{I} \beta d w_{21}^{I I}\left(\xi_{2}\right)-\varphi \Omega_{I} d w_{21}\left(\xi_{2}\right)\right] w_{21}\left(\xi_{2}\right) d \xi_{2}+}{+d \lambda_{I} \beta \int_{0}^{1} w_{31}^{I I}\left(\xi_{3}\right) w_{31}\left(\xi_{3}\right) d \xi_{3}-\varphi d \Omega_{I} \int_{0}^{1} w_{31}^{2}\left(\xi_{3}\right) d \xi_{3}+}
\end{aligned}
$$




$$
\begin{aligned}
& +\int_{0}^{1}\left[\mu w_{31}^{I V}\left(\xi_{3}\right)+\lambda_{I} \beta w_{31}^{I I}\left(\xi_{3}\right)-\varphi \Omega_{I} w_{31}\left(\xi_{3}\right)\right] d w_{31}\left(\xi_{3}\right) d \xi_{3}+ \\
& +\int_{0}^{1}\left[\mu d w_{31}^{I V}\left(\xi_{3}\right)+\lambda_{I} \beta d w_{31}^{I I}\left(\xi_{3}\right)-\varphi \Omega_{I} d w_{31}\left(\xi_{3}\right)\right] w_{31}\left(\xi_{3}\right) d \xi_{3}+ \\
& +d \lambda_{I} \beta \int_{0}^{1} w_{41}^{I I}\left(\xi_{4}\right) w_{41}\left(\xi_{4}\right) d \xi_{4}-\varphi d \Omega_{I} \int_{0}^{1} w_{41}^{2}\left(\xi_{4}\right) d \xi_{4}+ \\
& +\int_{0}^{1}\left[\mu w_{41}^{I V}\left(\xi_{4}\right)+\lambda_{I} \beta w_{41}^{I I}\left(\xi_{4}\right)-\varphi \Omega_{I} w_{41}\left(\xi_{4}\right)+K_{1} \mu w_{41}\left(\xi_{4}\right)\right] d w_{41}\left(\xi_{4}\right) d \xi_{4}+ \\
& +\int_{0}^{1}\left[\mu d w_{41}^{I V}\left(\xi_{4}\right)+\lambda_{I} \beta d w_{41}^{I I}\left(\xi_{4}\right)-\varphi \Omega_{I} d w_{41}\left(\xi_{4}\right)+K_{1} \mu d w_{41}\left(\xi_{4}\right)\right] w_{41}\left(\xi_{4}\right) d \xi_{4}=0
\end{aligned}
$$

It should be noted that underlined integrals in formula (44) are equal to zero (compare equation of motion (35)-(38)). From the natural boundary and continuity conditions (see Eqs. (23)-(28)) it follows that:

$$
\begin{gathered}
w_{11}^{I I}(1)+\mu w_{31}^{I I}(1)=0 \\
d w_{11}^{I I}(1)+\mu d w_{31}^{I I}(1)=0 \\
w_{11}^{I I I}(1)+\mu w_{31}^{I I I}(1)+\lambda(1+\beta)\left[w_{11}^{I}(1)-\frac{w_{11}(1)}{l_{b}^{*}}\right]+\frac{m \Omega_{I}}{(\rho A)_{1} L} w_{11}(1)=0 \\
w_{11}^{I I I}(1)+\mu w_{31}^{I I I}(1)=-\lambda(1+\beta)\left[w_{11}^{I}(1)-\frac{w_{11}(1)}{l_{b}^{*}}\right]-\frac{m \Omega_{I}}{(\rho A)_{1} L} w_{11}(1) \\
d w_{11}^{I I I}(1)+\mu d w_{31}^{I I I}(1)=-\lambda(1+\beta)\left[d w_{11}^{I I}(1)-\frac{d w_{11}(1)}{l_{b}^{*}}\right]-\frac{m w_{11}(1)}{(\rho A)_{1} L} d \Omega_{I}-\frac{m \Omega_{I}}{(\rho A)_{1} L} d w_{11}(1) .
\end{gathered}
$$

Using formulas (45)-(49) after prior integrating by parts of terms with second and fourth derivatives, relation (44) takes the form: 


$$
\begin{aligned}
& d F\left[w_{11}\left(\xi_{1}\right), w_{21}\left(\xi_{2}\right), w_{31}\left(\xi_{3}\right), w_{41}\left(\xi_{4}\right)\right]=\int_{0}^{1}\left[w_{11}^{I V}\left(\xi_{1}\right)+\lambda_{I} w_{11}^{I I}\left(\xi_{1}\right)-\Omega_{I} w_{11}\left(\xi_{1}\right)\right] d w_{11}\left(\xi_{1}\right) d \xi_{1}+ \\
& +\int_{0}^{1}\left[\mu w_{21}^{I V}\left(\xi_{2}\right)+\lambda_{I} \beta w_{21}^{I I}\left(\xi_{2}\right)-\varphi \Omega_{I} w_{21}\left(\xi_{2}\right)\right] d w_{21}\left(\xi_{2}\right) d \xi_{2}+ \\
& +\int_{0}^{1}\left[\mu w_{31}^{I V}\left(\xi_{3}\right)+\lambda_{I} \beta w_{31}^{I I}\left(\xi_{3}\right)-\varphi \Omega_{I} w_{31}\left(\xi_{3}\right)\right] d w_{31}\left(\xi_{3}\right) d \xi_{3}+ \\
& +\int_{0}^{1}\left[\mu w_{41}^{I V}\left(\xi_{4}\right)+\lambda_{I} \beta w_{41}^{I I}\left(\xi_{4}\right)-\varphi \Omega_{I} w_{41}\left(\xi_{4}\right)+K_{1} \mu d w_{41}\left(\xi_{4}\right)\right] d w_{41}\left(\xi_{4}\right) d \xi_{4}+ \\
& +d \lambda_{I}\left[(1+\beta) w_{11}(1) w_{11}^{I}(1)-\int_{0}^{1}\left[w_{11}^{I}\left(\xi_{1}\right)\right]^{2} d \xi_{1}-\beta \int_{0}^{1}\left[w_{21}^{I}\left(\xi_{2}\right)\right]^{2} d \xi_{2}+\right. \\
& \left.-\beta \int_{0}^{1}\left[w_{31}^{I}\left(\xi_{3}\right)\right]^{2} d \xi_{3}-\beta \int_{0}^{1}\left[w_{41}^{I}\left(\xi_{4}\right)\right]^{2} d \xi_{4}\right]+ \\
& +d \Omega_{I}\left[\int_{0}^{1} w_{11}^{2}\left(\xi_{1}\right) d \xi_{1}+\varphi \int_{0}^{1} w_{21}^{2}\left(\xi_{2}\right) d \xi_{2}+\varphi \int_{0}^{1} w_{31}^{2}\left(\xi_{3}\right) d \xi_{3}+\varphi \int_{0}^{1} w_{41}^{2}\left(\xi_{4}\right) d \xi_{4}+\frac{m w_{11}^{2}(1)}{(\rho A)_{I} L}\right]=0
\end{aligned}
$$

The first four integrals in formula (50) are equal to zero (see Eqs. (35)-(38)). After transformation of equation (50) the formula describing the slope of an eigenvalue curve of a geometrically nonlinear column loaded by force directed towards the positive pole locally resting on the Winkler elastic foundation was obtained:

$$
\begin{aligned}
& \frac{d \Omega_{I}}{d \lambda_{I}}= \\
& =\frac{-\int_{0}^{1}\left[w_{11}^{I}\left(\xi_{1}\right)\right]^{2} d \xi_{1}-\beta \int_{0}^{1}\left[w_{21}^{I}\left(\xi_{2}\right)\right]^{2} d \xi_{2}-\beta \int_{0}^{1}\left[w_{31}^{I}\left(\xi_{3}\right)\right]^{2} d \xi_{3}-\beta \int_{0}^{1}\left[w_{41}^{I}\left(\xi_{4}\right)\right]^{2} d \xi_{4}+(1+\beta) w_{11}(1) w_{11}^{I}(1)}{\int_{0}^{1} w_{11}^{2}\left(\xi_{1}\right) d \xi_{1}+\varphi \int_{0}^{1} w_{21}^{2}\left(\xi_{2}\right) d \xi_{2}+\varphi \int_{0}^{1} w_{31}^{2}\left(\xi_{3}\right) d \xi_{3}+\varphi \int_{0}^{1} w_{41}^{2}\left(\xi_{4}\right) d \xi_{4}+\frac{m w_{11}^{2}(1)}{(\rho A)_{I} L}} .
\end{aligned}
$$

The denominator in the formula (51) is always positive, so the sign of the equation depends only on the sign of the numerator. The result of the equation may be positive, negative or equal to zero depending on the values of elastic foundation parameters, external load and first natural frequency. In the case where $\left.\left(\frac{d \Omega_{I}}{d \lambda_{I}}\right)\right|_{\lambda_{I}=0}<0$ system is classified as a divergent type system and when 
$\left.\left(\frac{d \Omega_{I}}{d \lambda_{I}}\right)\right|_{\lambda_{I}=0}>0$ system is among the divergent pseudo-fluttering systems (see

Fig. 4). Ranges of values of a tendon's length parameter, for which the analysed system may be classified as one of two types mentioned above, were shown in Figure 5. The figure also illustrates the influence of stiffness of the Winkler elastic foundation on the type of the system. The presented results of numerical calculations refer to the selected values of coefficient of flexural stiffness distribution $\mu$, length and location of elastic base parameters.

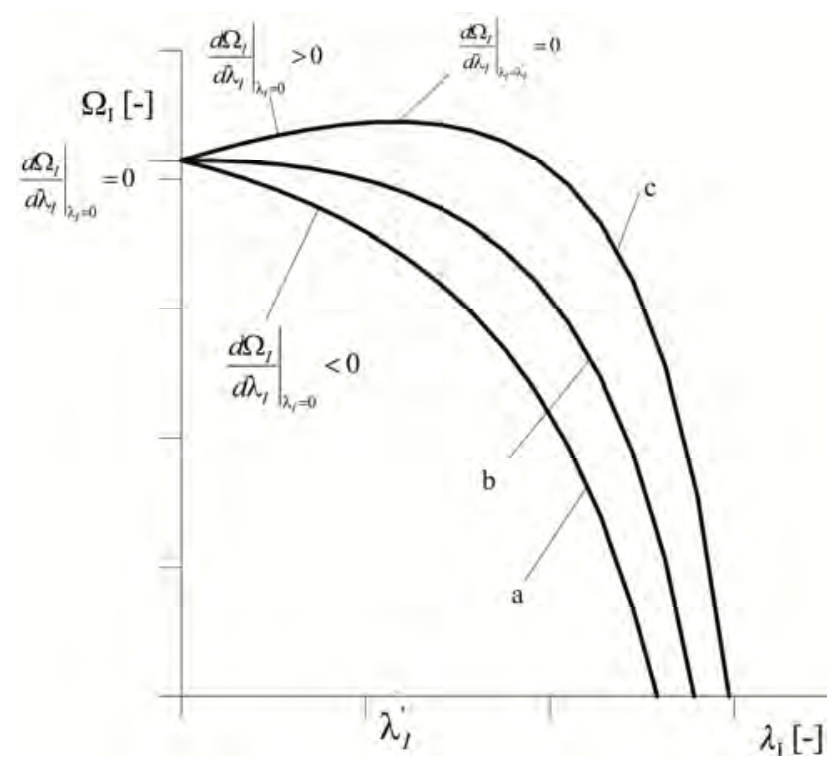

Fig. 4. Curves on the plane: external load parameter $\lambda_{\mathrm{I}}$ - first natural frequency parameter $\Omega_{\mathrm{I}}$ for: a), b) divergent, c) divergent pseudo-fluttering types of system

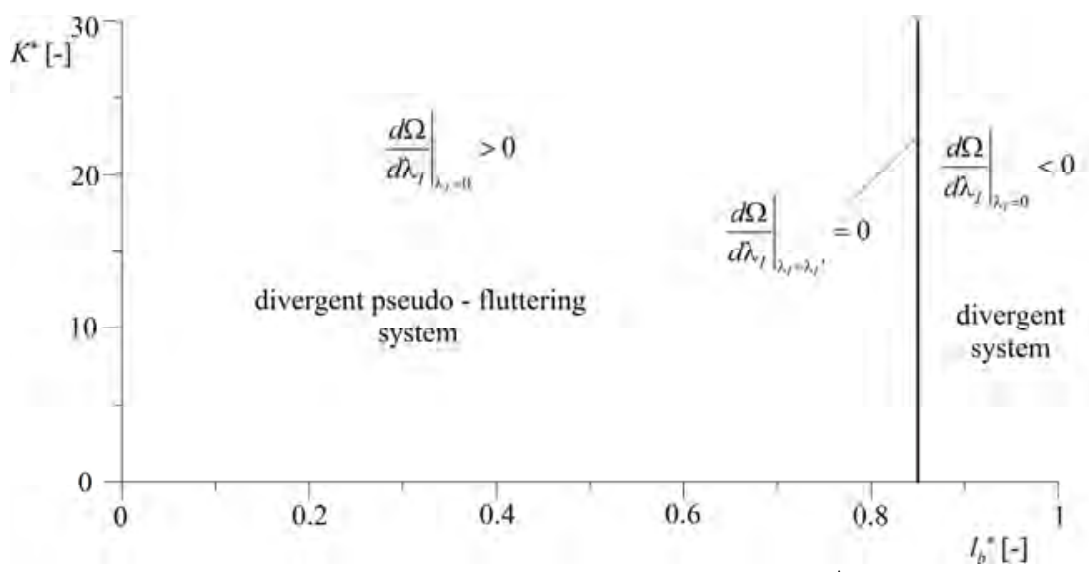

Fig. 5. The influence of stiffness of Winkler elastic foundation $K^{*}$ and tendon's length parameter $l_{b}{ }^{*}$ on the type of the system $\left(l_{c}{ }^{*}=0.5, l_{d}{ }^{*}=0.8, \mu=0.1\right)$ 


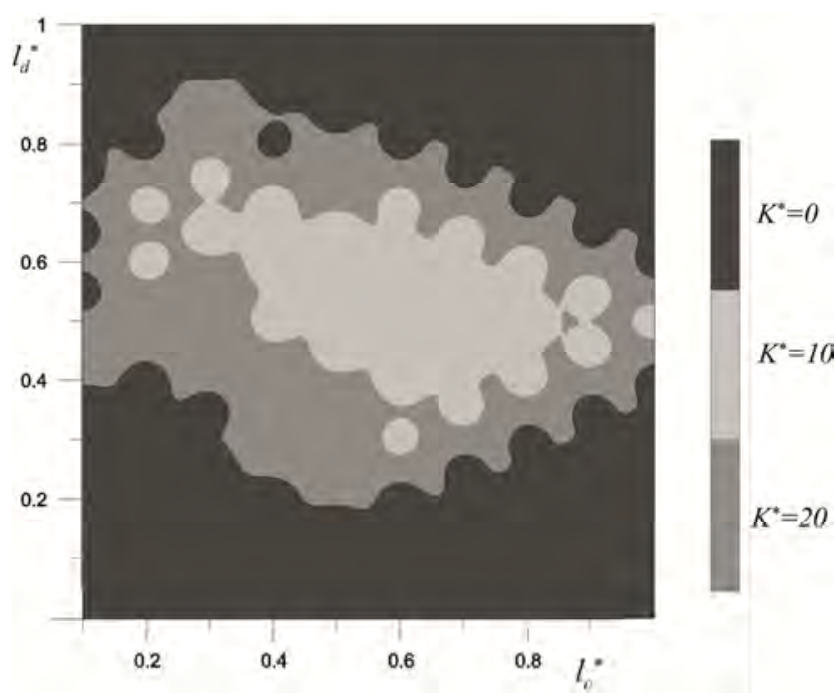

Fig. 6. Influence of parameters of length $l_{d}{ }^{*}$ and location $l_{c}{ }^{*}$ of the Winkler foundation on type of system $\left(l_{b}{ }^{*}=0.85, \mu=0.1\right)$

The influence of parameters describing length and location of the Winkler elastic foundation on the type of the system was presented in Figure 6 . When stiffness $K^{*}$ equals zero, the considered system is classified as the divergent pseudo-fluttering structure. Scopes of $l_{d}{ }^{*}$ and $l_{c}{ }^{*}$ parameters, for which the type of the system changes into divergent were marked using brighter shades, for elastic foundation stiffness equals $K^{*}=10$ and $K^{*}=20$, respectively.

\section{Conclusions}

The objective of the work was to obtain the criterion describing the influence of the stiffness of the Winkler elastic foundation parameter and the tendon's length parameter on the type of geometrically nonlinear column (divergent, divergent pseudo-fluttering) under a considered load directed towards the positive pole. On the basis of the presented results of numerical calculations, the following conclusions may be formulated:

- the system loaded by force directed towards the positive pole may be classified as one of two types: divergent or divergent pseudo-fluttering. The slope of the characteristic curves (curves on the plane free vibration frequency parameter - external load parameter) can take a negative, zero and positive value,

- taking into consideration a one-parameter Winkler elastic foundation in the physical model causes an increase of the value of free vibration frequency and critical load (the first natural frequency corresponding to the critical load),

- tendon's length parameter defining the direction of external load and the stiffness of the Winkler elastic foundation with a given parameters of length and location define belonging to one of two types of system. 


\section{Acknowledgements}

The study has been carried out within the framework of project BS/PB-1-101-3021/11/P realized at Czestochowa University of Technology.

\section{References}

[1] Bogacz R., Imiełowski S., Tomski L., Stability and vibration of column structures subjected to generalized concentrated load, Proceedings of International Symposium Dynamics of Continua, Physikzentrum Bad Honnef, 9-13 September 1996, 45-54.

[2] Szmidla J., Drgania swobodne i stateczność układów smukłych poddanych obciążeniu swoistemu, Seria Monografie 165, Wydawnictwo Politechniki Częstochowskiej, Częstochowa 2009.

[3] Tomski L., Szmidla J., Uzny S., Drgania i stateczność układów smukłych z elementami sprężystymi poddanych uogólnionemu obciążeniu Becka, rozdz. 9, Drgania swobodne i stateczność układów smukłych poddanych obciążeniu konserwatywnemu lub niekonserwatywnemu, praca zbiorowa pod kierunkiem naukowym i redakcją Lecha Tomskiego, Wydawnictwo Naukowe PWN, Warszawa 2012, 213-248.

[4] Leipholz H.H.E., On conservative elastic systems of the first and second kind, Ingenieur Archiv 1974, 43, 255-271.

[5] Tomski L., Przybylski J., Gołębiowska-Rozanow M., Szmidla J., Vibration and stability of an elastic column subject to a generalized load, Archive of Applied Mechanics 1996, 67, $105-116$.

[6] Tomski L., Przybylski J., Gołębiowska-Rozanow M., Szmidla J., Vibration and stability of a cantilever column subject to a follower force passing through a fixed point, Journal of Sound and Vibration 1998, 214(1), 67-81.

[7] Studziński R., Pozorski Z., Garstecki A., Sensitivity analysis of sandwich beams and plates accounting for variable support conditions, Bulletin of the Polish Academy of Sciences - Technical Sciences 2013, 61, 1, 201-210.

[8] Studziński R., Pozorski Z., Błaszczuk J., Optimal support system of sandwich panels, Journal of Engineering Mechanics 2015, 04014133, 141, 3, 1-8.

[9] Sato K., Nonlinear free vibration of beams with clamped ends and with one end clamped, other simply supported, Bulletin of JSME 1968, 11(48), 1027-1036.

[10] Meirovitch L., Analytical Methods in Vibration, Macmillan Company, New York 1967, 42-45. 